\title{
Glucose Tolerance and Plasma Insulin Levels During the Last Trimester of Pregnancy
}

\author{
TEIJI HAMADA, KIYOTAKA YOSHIMATSU, TOSHIYUKI OOSHIMA, \\ NORIO KUBO, JUNJI ISHIMATSU AND TOSHI KATO \\ Department of Obstetrics and Gynecology, Kurume University School of Medicine, \\ Kurnme, 830 Japan
}

Received for publication October 18, 1985

\begin{abstract}
Summary: Plasma glucose and plasma immunoreactive insulin (IRI) levels were measured during the $75 \mathrm{~g}$ glucose tolerance test (GTT) in healthy pregnant women, to clarify the changes of glucose metabolism during the last trimester of pregnancy. The glucose tolerance decreased with gestational time. After 33 weeks of gestation, the peak levels of the post-glucose loading occurred at 60 minutes instead of 30 minutes after glucose ingestion. The parameter that best reflected the decrease in glucose tolerance was the level 60 minutes after glucose ingestion, which at the $33 \mathrm{rd}$ gestational week was significantly higher than the level at the 28 th gestational week. The IRI reaction accompanying the rise in plasma glucose appeared to increase gradually during gestation, even in the last trimester. The largest increases of plasma IRI levels after glucose loading were seen at or after the 36 th week of gestation.
\end{abstract}

Key words: glucose tolerance $-75 \mathrm{~g}$ glucose load-last trimester of pregnancy - plasma glucose - plasma IRI

\section{Introduction}

Glucose tolerance decreases during pregnancy, especially in the last trimester, as compared to non-pregnant subjects. Few reports, however, give detailed data on the changes during the last trimester. In this study on normal pregnant females, the changes in glucose tolerance and plasma insulin (immunoreactive insulin, IRI) were measured after ingestion of glucose.

\section{Subjects and Methods}

The subjects in this study were outpatients in the Department of Obsterics and Gynecology who had no family history of diabetes, no history of previous heavyfor-date births, stillbirths or neonatal deaths of unknown causes, no history of hydramnious or severe toxicosis of pregnancy, no obesity of $20 \%$ or more above standard body weight, and who had neither hydramnious or severe toxicosis pregnancy nor complications of the fetus or neonate during the course of the present pregnancy. Complications of the fetus or neonate would include: heavy-for-date baby, asphyxia, respiratory distress syndrome, hypoglycemia, hyperbilirubinemia, polycythemia, and congenital anomaly. The pregnant women who had none of these complications were considered normal and given the $75 \mathrm{~g}$ glucose tolerance test (GTT). The principal subjects were those who took the test during the period from the 28 th to the 38 th week of gestation. The values for this group were compared with those for the group that 
had not yet reached the 28 th week.

Blood samples were taken from the cubital vein and plasma glucose levels were determined by the glucose oxidase method using an autoanalyzer. Plasma immunoreactive insulin (IRI) was measured by radioimmunoassay. Statistical analysis of the date was performed primarily by using the Student's t-test.

\section{Results}

1. Plasma glucose levels before and after ingestion of $75 \mathrm{~g}$ glucose by normal pregnant women at various gestatiomal times.

The results of the $75 \mathrm{~g}$ GTT in 243 normal pregnant females were compared according to the week of gestation. Table 1 shows the number of cases and the average plasma glucose level for each grop. Fig. 1. is a three-dimensional pattern obtained by plotting the plasma glucose levels against time after glucose loading and the gestational week at which the GTT was performed. Fig. 2. shows the one-dimensional regression equation for the correlation between the gestational week and the glucose levels at fasting, and 30, 60 and 120 minutes after ingestion of glucose. The data demonstrate that fasting plasma glucose levels decrease with increasing gestational time after the 28 th week. Incontrast, the post-glucose loading plasma glucose levels increase at each time of mesurement (30, 60, and 120 minutes). The most striking increase ocurred 60 minutes after glucose ingestion.

2. Plasma IRI levels before and after ingestion of $75 \mathrm{~g}$ glucose by normal pregnant women at various gestational times.

Plasma IRI levels after ingestion of glucose by 234 normal pregnant females at various gestational times were compared. Table 2 shows the number of cases and the average plasma IRI level for each gestational week at which the measurements were made. Fig. 3 and 4 show the plasma IRI data illustrated by the same methods used in Fig. 1 and 2. The fasting plasma IRI levels did not vary during the last trimester. The plasma IRI levels. 30, 60 and 120 minutes after ingestion of glucose, all showed marked rises with increasing gestational time. The rise at 60 minutes was especially pronounced.

TABLE 1

Plasma glucose levels before and after $75 \mathrm{~g}$ glucose loading in normal pregnant women at the 28 th to the 38 th gestational week

\begin{tabular}{cccccc}
\hline \multirow{2}{*}{$\begin{array}{c}\text { Gestational } \\
\text { week }\end{array}$} & \multirow{2}{*}{$\begin{array}{c}\text { No. of } \\
\text { cases }\end{array}$} & \multicolumn{4}{c}{$75 \mathrm{~g}$ GTT $(\mathrm{M} \pm \mathrm{SD} \mathrm{mg} / \mathrm{dl})$} \\
\cline { 3 - 6 } & & fast & $30 \mathrm{~min}$ & $60 \mathrm{~min}$ & $120 \mathrm{~min}$ \\
\hline 28 & 13 & $85 \pm 8$ & $126 \pm 18$ & $108 \pm 30$ & $103 \pm 18$ \\
29 & 25 & $84 \pm 7$ & $127 \pm 21$ & $119 \pm 28$ & $107 \pm 22$ \\
30 & 43 & $84 \pm 7$ & $126 \pm 16$ & $118 \pm 25$ & $109 \pm 15$ \\
31 & 36 & $84 \pm 6$ & $127 \pm 17$ & $125 \pm 31$ & $104 \pm 17$ \\
32 & 30 & $86 \pm 8$ & $128 \pm 19$ & $125 \pm 29$ & $108 \pm 21$ \\
33 & 27 & $83 \pm 6$ & $129 \pm 16$ & $132 \pm 26$ & $107 \pm 14$ \\
34 & 17 & $84 \pm 8$ & $134 \pm 16$ & $141 \pm 21$ & $115 \pm 13$ \\
35 & 18 & $82 \pm 12$ & $131 \pm 19$ & $137 \pm 29$ & $118 \pm 21$ \\
36 & 14 & $83 \pm 6$ & $128 \pm 15$ & $129 \pm 22$ & $103 \pm 15$ \\
37 & 13 & $83 \pm 8$ & $132 \pm 14$ & $143 \pm 28$ & $108 \pm 20$ \\
38 & 7 & $83 \pm 10$ & $131 \pm 24$ & $129 \pm 39$ & $107 \pm 16$ \\
\hline
\end{tabular}




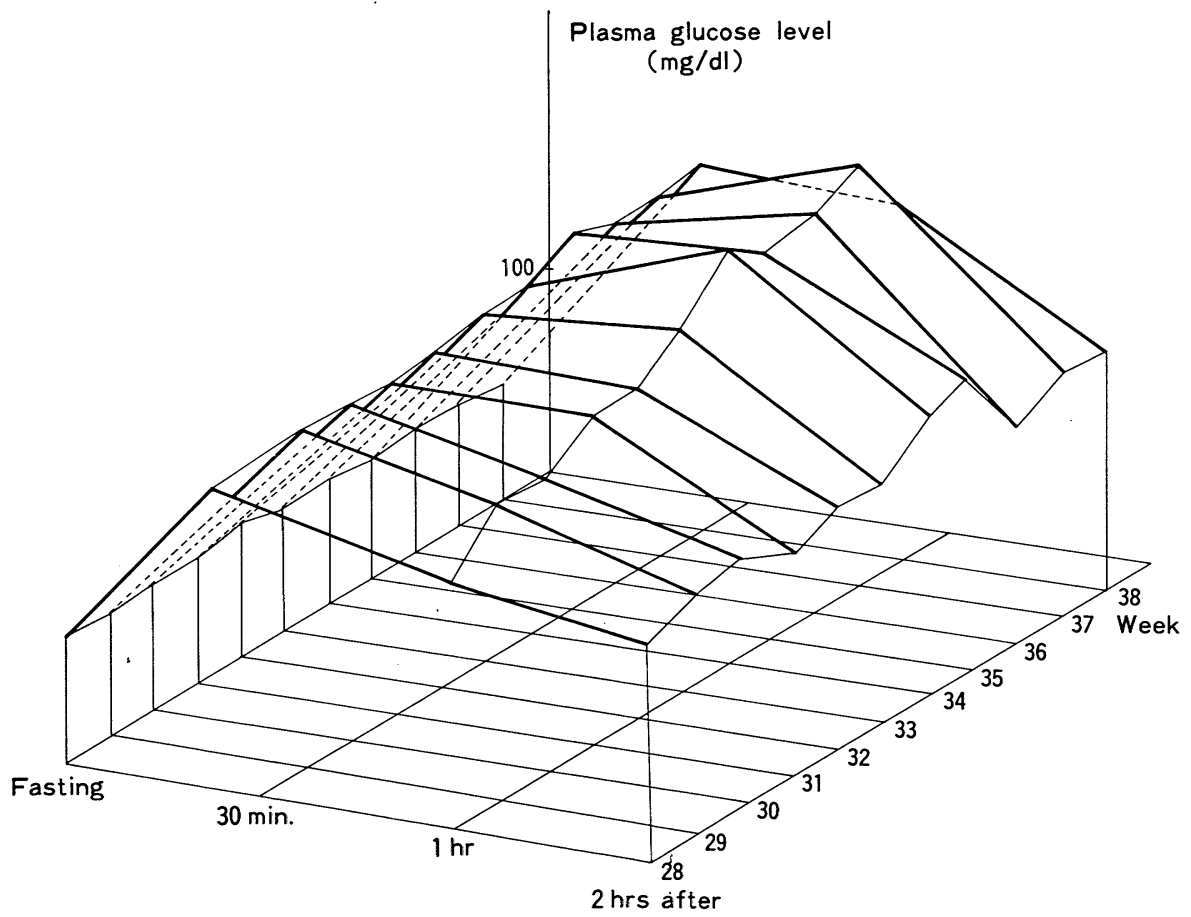

Fig. 1. Plasma glucose levels before and after $75 \mathrm{~g}$ glucose loading in normal pregnant women at the 28 th to the 38 th gestational week $(N=243)$

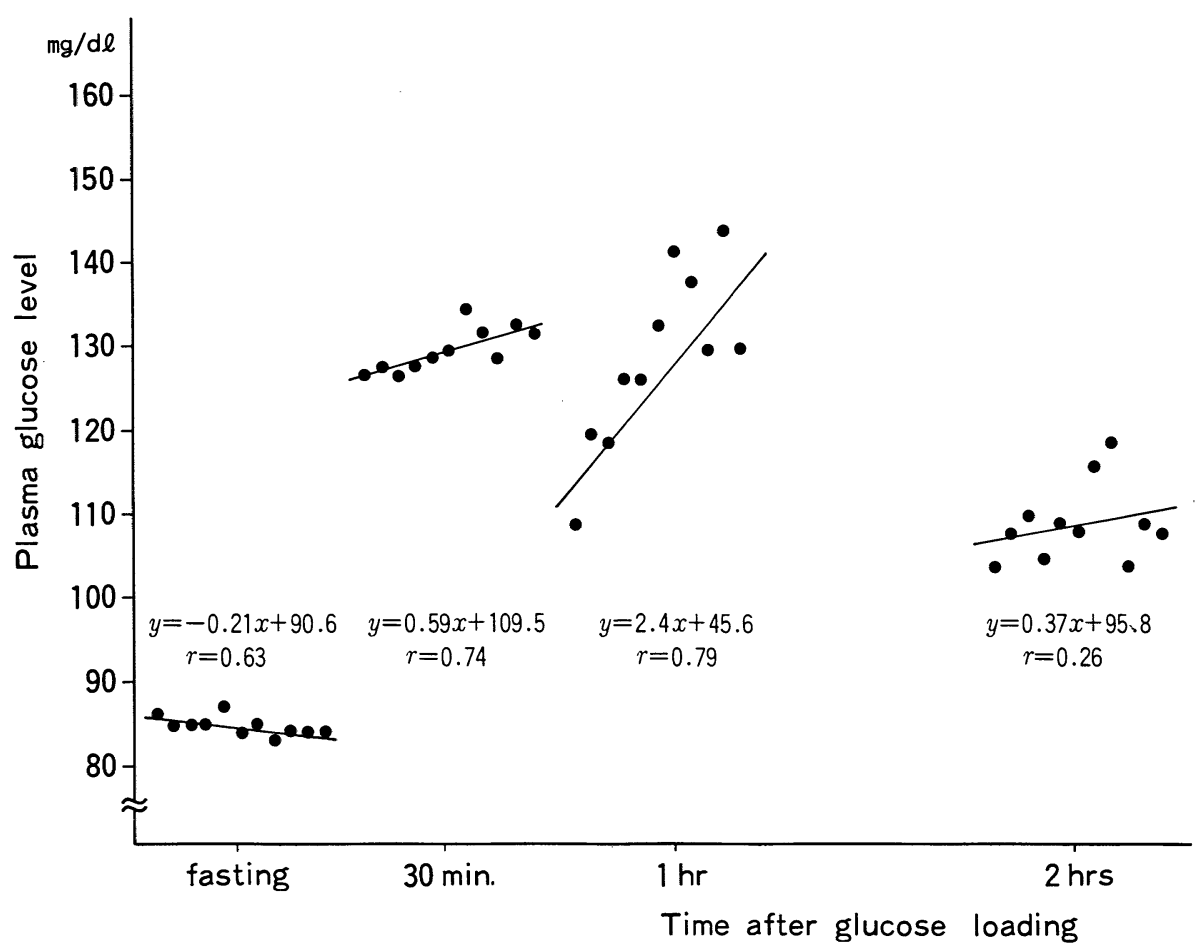

Fig. 2. Plasma glucose levels before and after $75 \mathrm{~g}$ glucose loading in normal pregnant women at the 28 th to the 38 th gestational week $(N=243)$ 
TABLE 2

Plasma IRI levels before and after glucose loading in normal pregnant women at the 28th to the 38th gestational week

\begin{tabular}{ccrccc}
\hline \multirow{2}{*}{$\begin{array}{c}\text { Gestational } \\
\text { week }\end{array}$} & \multirow{2}{*}{$\begin{array}{c}\text { No. of } \\
\text { cases }\end{array}$} & \multicolumn{4}{c}{$75 \mathrm{~g}$ GTT $(\mathrm{M} \pm \mathrm{SD} \mu \mathrm{U} / \mathrm{ml})$} \\
\cline { 3 - 6 } & & fast & $30 \mathrm{~min}$ & $60 \mathrm{~min}$ & $120 \mathrm{~min}$ \\
\hline 28 & 12 & $5 \pm 3$ & $48 \pm 18$ & $44 \pm 31$ & $33 \pm 18$ \\
29 & 23 & $7 \pm 7$ & $49 \pm 30$ & $45 \pm 27$ & $35 \pm 27$ \\
30 & 40 & $7 \pm 7$ & $52 \pm 34$ & $48 \pm 29$ & $41 \pm 28$ \\
31 & 34 & $9 \pm 10$ & $56 \pm 32$ & $63 \pm 40$ & $40 \pm 32$ \\
32 & 29 & $6 \pm 4$ & $57 \pm 27$ & $55 \pm 30$ & $50 \pm 33$ \\
33 & 27 & $10 \pm 9$ & $60 \pm 39$ & $65 \pm 37$ & $46 \pm 34$ \\
34 & 17 & $7 \pm 6$ & $52 \pm 41$ & $63 \pm 40$ & $42 \pm 32$ \\
35 & 18 & $9 \pm 14$ & $51 \pm 30$ & $63 \pm 39$ & $55 \pm 35$ \\
36 & 14 & $6 \pm 6$ & $58 \pm 23$ & $61 \pm 34$ & $40 \pm 33$ \\
37 & 13 & $6 \pm 4$ & $62 \pm 35$ & $69 \pm 34$ & $33 \pm 12$ \\
38 & 7 & $8 \pm 9$ & $64 \pm 31$ & $78 \pm 46$ & $78 \pm 50$ \\
\hline
\end{tabular}

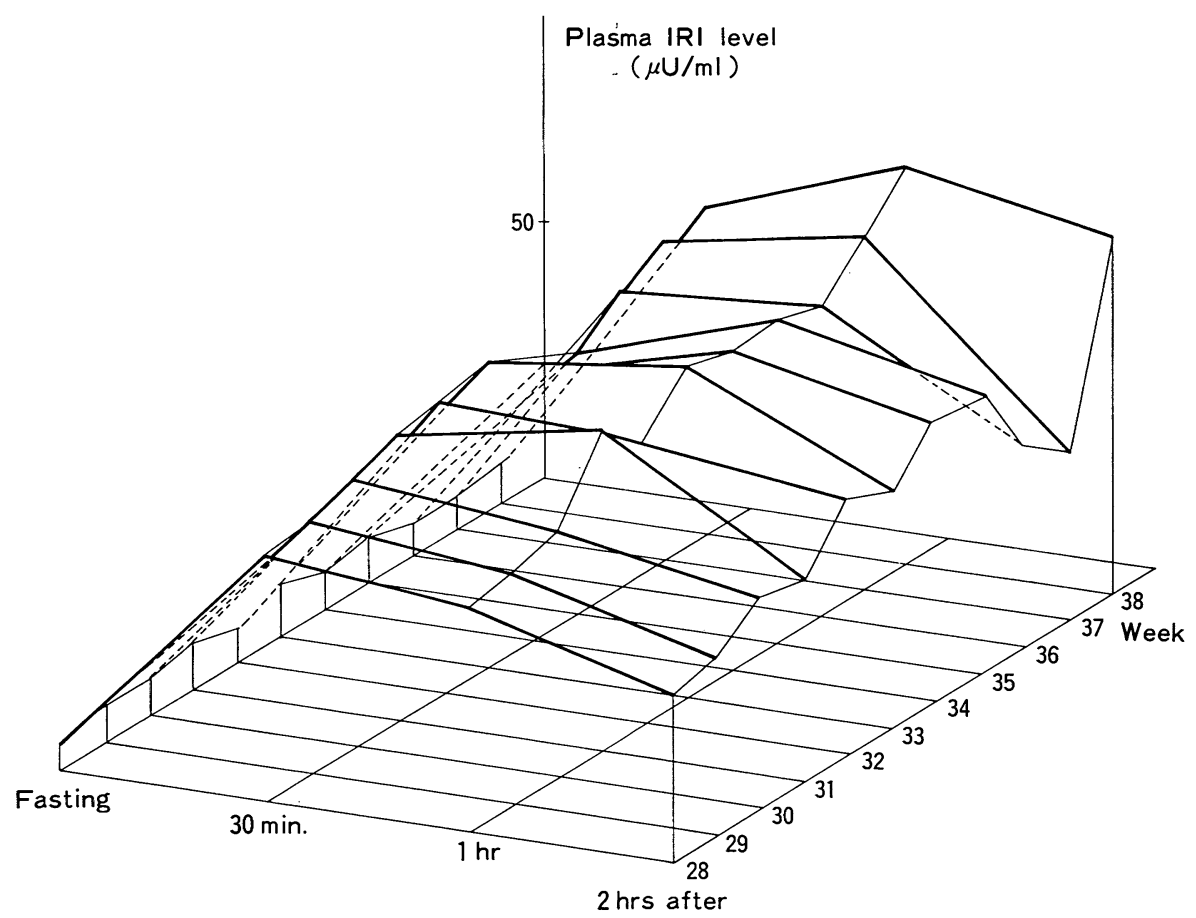

Fig. 3. Plasma IRI levels before and after $75 \mathrm{~g}$ glucose loading in normal pregnant women at the 28 th to the 38 th gestational week $(\mathrm{N}=234)$ 


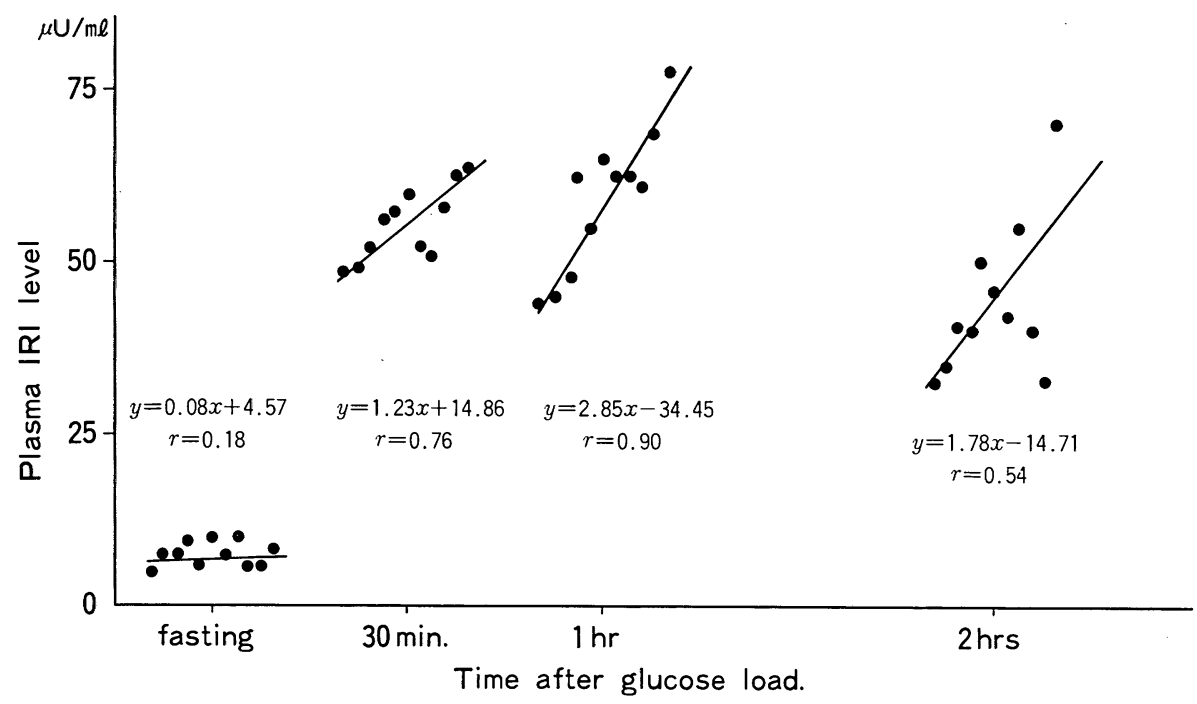

Fig. 4. Plasma insulin levels before and after $75 \mathrm{~g}$ glucose loading in normal pregnant women at the 28 th to the 38 th gestational week $(\mathrm{N}=234)$

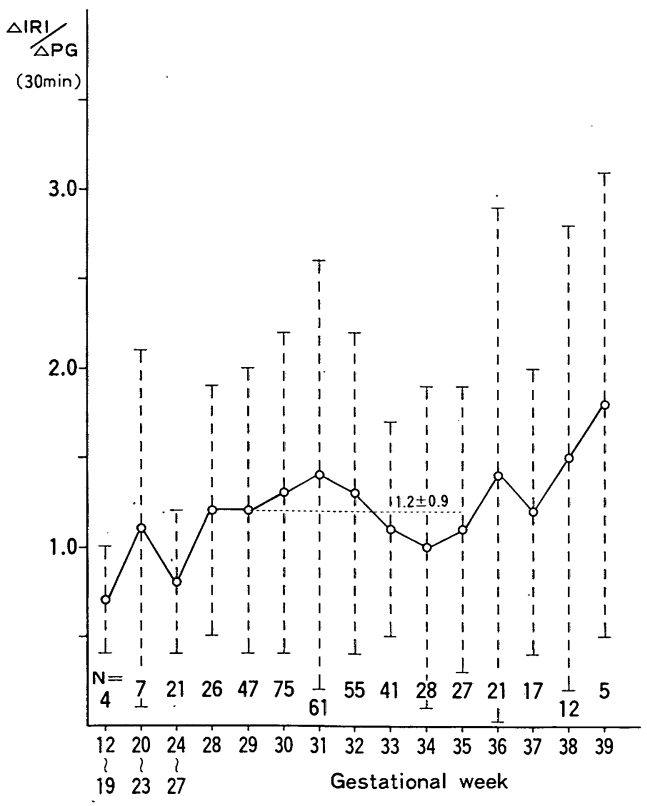

Fig. 5. Insulinogenic index (IRI/PG. $30 \mathrm{~min}$.) after $75 \mathrm{~g}$ glucose loading in normal pregnant women at the 28 th to the 39 th gestational week $(\mathrm{N}=447)$
3. Insulinogenic index in normal pregnant women given the $75 \mathrm{~g}$ GTT.

The insulinogenic index (I.I.) is the ratio between the increase of plasma IRI and the increase of plasma glucose (PG), 30 minutes after the ingestion of $75 \mathrm{~g}$ glucose $(\Delta \mathrm{IRI} / \Delta \mathrm{PG})$. The insulinogenic indices of normal pregnant females at different gestational times were compared and were found to be higher during the last trimester than during the second trimester of pregnancy. From the 28 th to the 35 th week, the index did not change, but at the 36 th and later weeks, the index again rose sharply (Fig. 5).

\section{Discussion}

Changes in glucose tolerance during pregnancy have been the subject of many reports. The current view is that fasting plasma glucose levels are lower during pregnancy than at other times and the reduction becomes larger during the later stages of pregnancy (Bleicher et al. 1964; Lind 1980; Victor 1974). It is also thought 
that post-glucose-loading glucose tolerance also gradually decreases during the pregnancy (Daniel et al. 1974; Fisher et al. 1974; Kalkhoff et al. 1970; Kühl 1975; O'Sullivan et al. 1970; Silverstone et al. 1961). These changes in glucose tolerance have been studied when glucose loading is performed either by oral ingestion (Daniel et al. 1974; Kalkhoff et al. 1970; Kühl. 1975; Silverstone et al. 1961) or intravenous injection (Benjamin and Casper 1966; Fisher et al. 1974; O'Sullivan et al. 1970). In almost all studies using oral ingestion methods, $50 \mathrm{~g}$ (Kühl 1975; Lind et al. 1973) or $100 \mathrm{~g}$ (Daniel et al. 1974; Hansen and Kallner 1984; Kalkhoff et al. 1970; Silverstone et al. 1961) of glucose is given. In the present study of glucose tolerance, an intermediate dose of $75 \mathrm{~g}$ was administered. The objective was to investigate glucose tolerance during the second and last trimesters of pregnancy. The last trimester is considered to be a period when glucose tolerance is prone to decrease. Methods were used to determine whether small fluctuations occur. To identify the changes of glucose tolerance in this period, subjects were selected who were pregnant but had neither complications nor episodes related to abnormalities of glucose metabolism.

Judging from the GTT findings in this study obtained during a normal pregnancy, the fasting plasma glucose levels decrease with increasing gestational time, even within the last trimester. Glucose tolerance decreases with increasing gestational time, as is shown clearly by 1) the observation that after the $33 \mathrm{rd}$ week of gestation, the peak of the rise in plasma glucose occurs later, at 60 minutes instead of 30 minutes after glucose ingestion; and 2) by the positive correlation between gestational week and plasma glucose at different times after glucose ingestion. The parameter that best reflected the decrease in glucose tolerance was the level 60 minutes after glucose injection, which at 33 gestational weeks reached the significantly high level of $134 \pm 24 \mathrm{mg} / \mathrm{dl}$, compared to $113 \pm 30 \mathrm{mg}$ /dl at 28 weeks. This indicates that there is a pronounced decrease in glucose tolerance during the last trimester, beginning at or around the $33 \mathrm{rd}$ week. This finding agrees with the clinically observed onset of metabolic disturbances, inclding ketoacidosis, that begin to increase in frequency at the 34 th gestational week in pregnant diabetic females.

Next, the changes in plasma IRI after $75 \mathrm{~g}$ GTT were observed. As previously mentioned, the fasting plasma IRI level during pregnancy tends to increase (Spellacy and Goetz, 1963) and the post-glucose loading response is augmented (Daniel et al. 1974; Kalkhoff et al. 1970; Lind et al. 1973; Spellacy and Goetz, 1963; Spellacy et al. 1965; Spellacy et al. 1965). During pregnancy, the anabolic phases in the mother and the fetus are gradually potentiated, while the accelerated secretion of corticosteroids and hPL by the mother after the 20 th gestational week brings about a relative potentiation of maternal catabolism (Freinkel et al. 1979). Therefore in the anabolic state caused by glucose loading, greater quantities of insulin are requived than when the mother is not pregnant.

Reflecting on this pattern of insulin secretion, the postglucose loading plasma IRI levels tended towards hypersecretion in comparison to non-pregnancy levels. These trends are explained by the rise with increasing gestational time in the post-glucose loading plasma IRI levels at each time of measurement, especially at 60 minutes after the ingestion of glucose (correlation ratio $r=0.90$ ). Fig. 5. shows the relationship between gestational week and insulinogenic index, which should closely reflect insulin secretory function. The augmentation of insulin secretion continuid to rise sharply from the first trimester through the second trimester until the 31 st week, when it plateaued moment 
arily and then began another rising phase in the 35 th week.

To summarize, a decrease in glucose tolerance, as indicated by the rise in plasma glucose after ingestion of $75 \mathrm{~g}$ glucose, and the augmented insulin secretion accompanying the rise in plasma glucose both appear to increase gradually during gestation, even during the last trimester. The decrease in glucose tolerance at approximately the 36 th gestational week is particularly marked and is acompanied by a pronounced simultaneous increase in insulin requirement.

\section{References}

Benjamin, F., and CAsper, D. J. (1966). Oral versus intravenous glucose tolerance test during pregnancy. Am. J. Obstet. Gynecol. 94, 566570 .

Bleicher, S. J., O’Sullivan, J.B. and Freinkel, N. (1964). The interrelations of glucose, insulin and free fatty acids in late pregnancy and postpartum. N. Eng. J. Med. 271, 866-872.

Daniel, R.R., Metzger, B.E., Freinkel, N., FALOONA, G., Unger, R.H. and Nitzen, M. (1974). Carbohydrate metabolism in pregnancy. Diabetes, 23, 771-776.

Fisher, P.M., Hamilton, P.H. and Sutherland, H.W. (1974). The effect of pregnancy on intravenous glucose tolerance. J. Obstet. Gynaec. Brit. Cmmw. 81, 285-290.

Freinkel, N., Phelps, R.L. and Metzger, B.E. (1979). Intermediarly metabolism during normal pregnancy, in Carbohydrate Metabolism in Pregnancy and the Newborn. ed. Sutherland, H.W. and Stower, J.M. p. 1-31. Berlin:
Springer.

Hansen, U. and Kallner, A. (1984). Oral glucose tolerance in pregnancy. Acta Obstet. Gynecol. Scand. 63, 249-252.

Kalkhoff, R.K., Jacobson, M. and Lemper, D. (1970). Progesterone, pregnancy and the augmented plasma insulin response. J. Clin. Endocrinol. Metab. 31, 24-28.

KÜHL,C. (1975). Glucose metabolism during and after pregnancy in normal and gestational diabetic women. Acta Endocrinol. 79, 709719.

Lind, T., Billewicz, W.Z. and Brown, G. (1973). A serial study of changes occuring in the oral glucose tolerance test during pregnancy. J. Obstet. Gynaec. Brit. Cmmw. 80, 10331039.

Lind, T. (1980). Plasma glucose control during pregnancy, in Clinical Physiology in Obstetrics. Hytten, F. and Chamberlain, G. p. 241256. London: Blackwell Scientific Pub.

O’Sullivan, J, B., Snyder, P. J., Sporer, A. C., DanDROW, R.V. and ChARLES, D. (1970). Intravenous glucose tolerance test and its modifications by pregnancy. J. Clin. Endocr. 31, 3337.

Silverstone, F. A., Solomon, E. and Rubricius, J. (1961). The rapid intravenous glucose tolerance test in pregnancy. J. Clin. Invest. 40, 2180-2189.

Spellacy, W.N. and Goetz, F.C. (1963). Plasma insulin in normal late pregnancy. N. Eng. J. Med. 268, 988-991.

Spellacy, W.N., Goetz, F.C., Greenberg, B.Z. and ELLS, J. (1965). Plasma insulin in normal "early" pregnancy. Obstet. Gynecol. 25, 862868.

Spellacy, W. N., Goetz, F.C., Greenberg, B. Z. and Elis, J. (1965). Plasma insulin in normal midpregnancy. Am. J. Obstet. Gynecol. 92, 1116. 